\title{
NUMERICAL DESIGN AND ANALYSIS ISOLATED SINGLE SPAN PEDESTRIAN BRIDGE UNDER SEISMIC LOAD
}

\author{
Al Amin \\ Graduate Student, Department of civil engineering, \\ University of Asia pacific, Dhaka-1230, Bangladesh
}

\begin{abstract}
In recent time earthquake has been the most dangerous threat to structures. As Bangladesh has a high risk of facing earthquake it is necessary to ensure safety of the structures. Bridges are very vulnerable to earthquake ground motion. In this study a single span composite bridge is modelled with SAP 2000 and is analysed. The bridge is analysed without using isolators subjected to modified EI Centro data for 15, 20 seconds. Nonlinear time history analysis was performed. Then this same bridge is analysed using a lead rubber bearing at one end of the bridge. The behaviour of the bridge is observed using isolators. From this analysis displacement vs time and acceleration vs time curves are found for different El Centro data. For base isolated and not isolated condition this results are compared. The comparison shows how seismically isolated condition can improve the response of bridge during earthquake.
\end{abstract}

Keywords-isolators, El Centro data, lead rubber bearing etc.

\section{INTRODUCTION}

Technologies for seismic protection have been developed, in order to design structures in highly seismic hazardous area. One of the most interesting solutions applied in bridges are passive energy dissipation systems [1]. Isolation systems can be steel hysteretic dampers or viscous dampers. Bridges built in seismically sensitive regions require special consideration in their structural design. Performing an accurate and realistic numerical simulation of the seismic response of the pedestrian bridges presents a significant challenge to the field of earthquake engineering. Base isolation results in increasing the natural period and damping characteristics of the bridges. Isolation devices have the ability to increase period of vibration of the structure towards a lower amplification range of the response spectrum for design ground motion, thus reducing the input energy or force demand into the structure.to control these increased deflections within desirable limits. Reducing the effect of the lateral displacement and horizontal forces generated from earthquake motion is of great concern to designers. The structural bearing technique is one of the tools to reduce the lateral displacement of the bridges.

\section{LITERATURE REVIEW}

Base isolation was firstly registered as a patent in 1800 's, with Lead Rubber Bearing (LRB) providing high flexibility and damping. The natural rubber has been used for base isolation since 1840 's, through the process of material development synthetic rubber or poly-tetra-fluoro-ethylene (PTFE) which is developed by DuPont was used, and designed for 50 years or more [9].

Unjoh and Ohsumi (1998) have conducted numerical study on the earthquake response characteristics and the design method of the multi-span continuous girder bridge with seismic isolation design concept [3].

Ghobarah and Ali (1988); Turkington et al. (1989a); Turkington et al. (1989b) and Jangid (2004) Have evaluated the suitability of using LRBs in reducing the seismic responses of bridges[7]. Su et al. (2002) and Pagnini et al. (1998), Tongaokar and Jangid (2000) have evaluated the effect of modeling of the isolation bearings on seismic Responses of bridges. Paragraph content goes here. Paragraph content goes here. Paragraph content goes here. Paragraph content goes here. Paragraph content goes here. Paragraph content goes here. Paragraph content goes here. Paragraph content goes here [10].

\section{DESIGN OF LEAD RUBBER BEARINGS}

\section{A. Lead rubber bearings (LRBs)}

Lead Rubber Bearings (LRB) consists of a laminated rubber and steel bearing with steel flange plates for mounting to the structure. Ninety percent of our isolators have an energy dissipating lead core. The rubber in the isolator acts as a spring. It is very soft laterally but very stiff vertically. The high vertical stiffness is achieved by having thin layers of rubber reinforced by steel shims. These two characteristics allow the isolator to move laterally with relatively low stiffness yet carry significant axial load due to their high vertical stiffness [12]. The lead core provides damping by deforming plastically when the isolator moves laterally in an earthquake. 


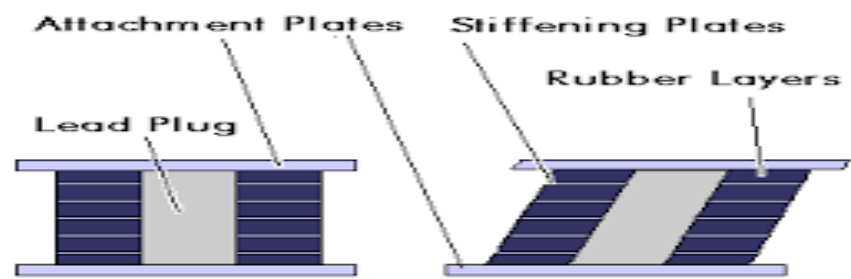

Figure 1. Lead Rubber Bearing

\section{B. Conceptual design of lead rubber bearing}

There are two of the most commonly used procedures for designing bridges with lead-rubber bearings are: (1) In New Zealand, the Ministry of Works and Development (MWD) design guide (1983); and (2) in California, the Dynamic Isolation Systems (DIS) procedure (1984). Both procedures in figure 2.4 represent the seismic response of the bridge by a single-degree-of-freedom (SDOF) structure with inelastic spectra.

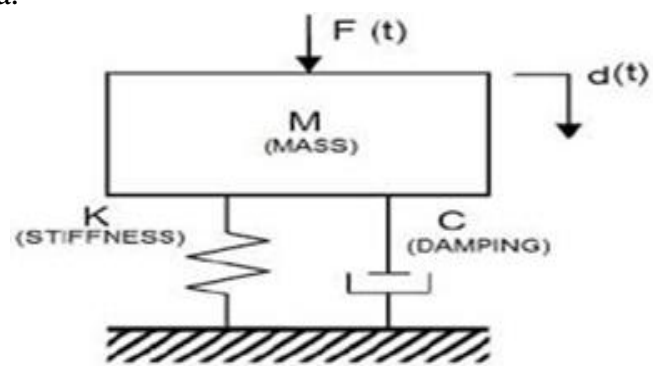

Figure 2. Single degree freedom (SDOF) system

Where, $\mathrm{M}$ is the Mass, $\mathrm{K}$ is the stiffness, $\mathrm{C}$ is the damping and $\mathrm{F}(\mathrm{t})$ is the vibration with respect to time of the system. Figure 2.5 shows free body diagram of single degree of freedom system (SDOF). Where, $\mathrm{f}_{\mathrm{i}} \mathrm{i}=$ Inertia force $=$ Mass times Acceleration $\left.=\mathrm{M} \llbracket \mathrm{X}^{\prime \prime}\right], \mathrm{f} \_\mathrm{v}=$ Viscous force $=$ Viscous damping times with velocity $\left.=\mathrm{C} \llbracket \mathrm{X}^{\prime}\right], \mathrm{f}_{-} \mathrm{s}=$ spring force $=$ Stiffness times Displacement $=\mathrm{KX}$. The damping ratio is a parameter, usually denoted by $\zeta$ (zeta) that characterizes the frequency response of a second order ordinary differential equation. $\zeta=$ actual damping (C) / critical damping $(\mathrm{Cc})$. the critical damping coefficient is $\mathrm{Cc}=2 \sqrt{\mathrm{km}}$ or $2 \mathrm{~m} \omega \mathrm{n}$. The lengthening of the first-mode period results into the reduction of the earthquake-induced forces in the structure, but only for short period structures. For long period structures, this effect might be negligible.

\section{Design Procedure for isolated Bridge}

In the model, the effective stiffness $\mathrm{K}$, and the equivalent damping ratio, $\xi$, are considered constant during the time of earthquake. These parameters are determined from the hysteresis loop of a bearing obtained for the design displacement, D; [15]

$\mathrm{K}=(\mathrm{F}(\mathrm{D})-\mathrm{F}(-\mathrm{D})) / 2 \mathrm{D}$

(1); $\quad \xi=\Delta \mathrm{W} / 2 \pi \mathrm{W}$
Where; $F(D)$ is a lateral force at displacement $D, \Delta W s$ is an energy dissipated in each cycle (area enclosed by the hysteresis loop) and Ws is a strain energy induced in a bearing;

$\mathrm{Ws}=\mathrm{F}(\mathrm{D}) * \mathrm{D} \quad \ldots \ldots \ldots$ (3); $\quad \mathrm{K}_{\mathrm{eff}}=\mathrm{k}_{\mathrm{r}}+\mathrm{Q}_{\mathrm{d}} / \mathrm{D}$

Where, the effective stiffness is computed using the maximum displacement of the deck; the characteristic yield strength of lead, $Q_{d}$ and the post-elastic stiffness of the bearing; $\mathrm{k}_{\mathrm{r}}$.

\section{Response Spectrum for Isolated Bridge}

According to AASHTO (1999) codes, the design spectrum for isolated bridges differs from conventional bridges. The design spectrum is specified in terms of a design displacement $D$ rather than spectral acceleration, which is a function of the effective period $\mathrm{T}_{\text {eff }}$ and damping ratio of the bridge, $\zeta_{\text {iso }}$

$$
\mathrm{D}=\frac{10 \mathrm{AS}_{\mathrm{i}} \mathrm{T}_{\mathrm{eff}}}{C} \text { (inches) } \ldots . .(5) \quad \mathrm{T}_{\mathrm{eff}}=2 \pi \sqrt{\frac{\mathrm{W}}{\mathrm{g} \times \mathrm{K}_{\mathrm{eff}}}} \ldots
$$

$\mathrm{C}$ is a damping factor that depends on the damping ratio $\zeta_{\text {iso }}, \mathrm{A}$ is the acceleration coefficient for the site, and $\boldsymbol{S}_{\mathrm{i}}$ is the site coefficient for isolated structure. In this study, the acceleration coefficient A (which represents peak ground acceleration) is replaced by the 1.0 second period spectral acceleration coefficient $\boldsymbol{S}_{1}$ (Buckle et al., 2006a). Figure 3.2 shows Response spectra for the bridges with conventional and isolated conditions with respect to natural period.

According to the displacement $\mathrm{D}$ can be estimated the total lateral force in the system., $\mathrm{F}=\mathrm{K}_{\mathrm{eff}} * \mathrm{D}$

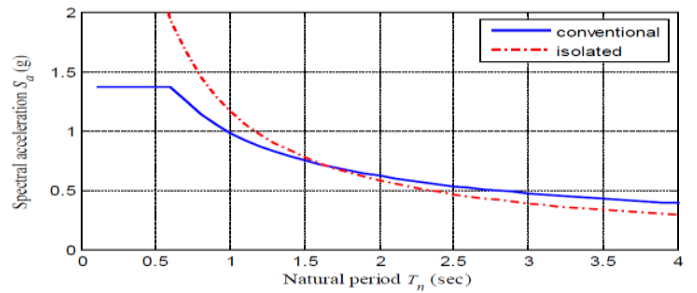

Figure 3. Response spectra for the bridges with different base conditions

\section{E. Isolated Bridge with linear device}

The performance of the columns will degrade once their elastic limit has been reached and larger displacement demands will be imposed on the substructure then the bridge is analysed using the design spectrum for the isolated bridge.

$\mathrm{K}_{\text {total }}$ Or $\mathrm{K}_{\text {iso }}=\frac{\mathrm{w}}{\mathrm{g}}\left(\frac{2 \Pi}{\mathrm{T}_{\mathrm{n}}}\right)^{2}$

Based on the total weight $\mathrm{W}$ and assumed natural period T_n of the bridge; the total stiffness, K_total and design base shear, F. The design base shear of the whole bridge $F_{\text {_yis }}$ calculated from the elastic base shear

$\mathrm{F}$ and force reduction $\mathrm{R}$; The total displacement demand $\mathrm{D}$ is distributed to the isolators to their stiffness is;

$$
\mathrm{F}_{y}=\frac{\mathrm{F}}{\mathrm{R}}
$$

$$
\mathrm{U}_{\mathrm{iso}}=\frac{D}{1 * \mathrm{~K}_{\text {iso }}}
$$




\section{NUMERICAL MODELLING AND ANALYSIS}

Using SAP2000 18 the model of a single span Pedestrian Bridge that consists of steel truss members and concrete deck slab, shown figure 4

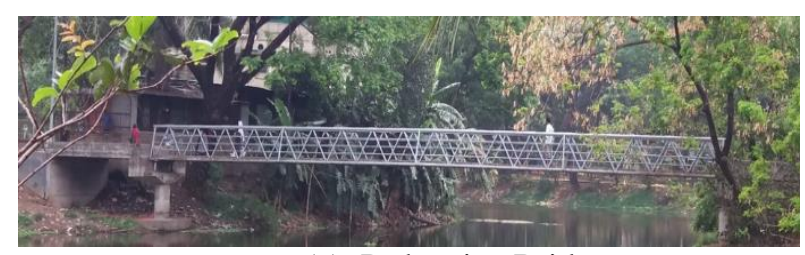

(a). Pedestrian Bridge

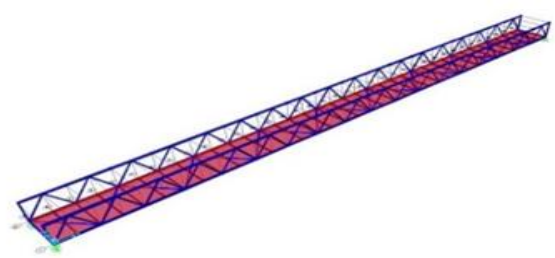

(b) 3D view of bridge in SAP 2000

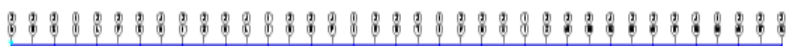
WNWNWNWNWNWN

(c) xz plane view of bridge in SAP 2000

\section{A. Material properties}

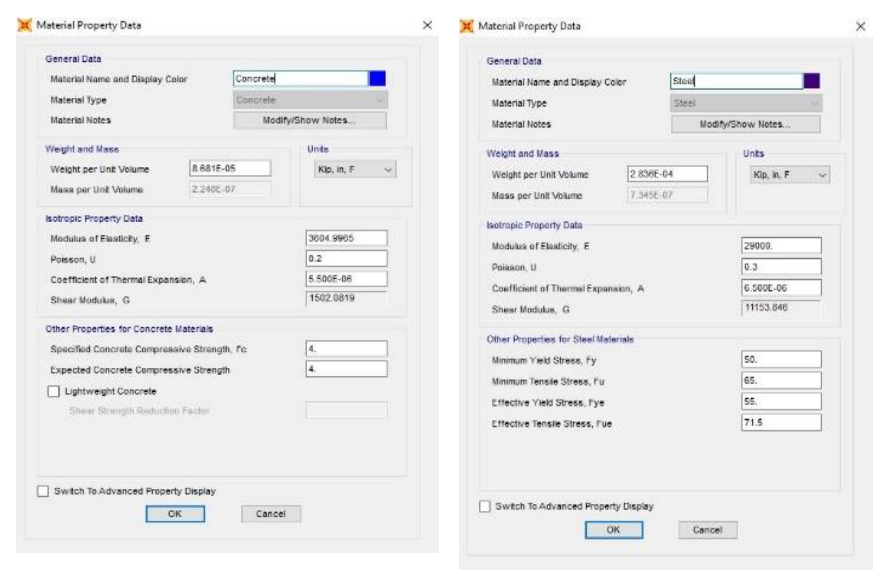

\section{B. Section properties}
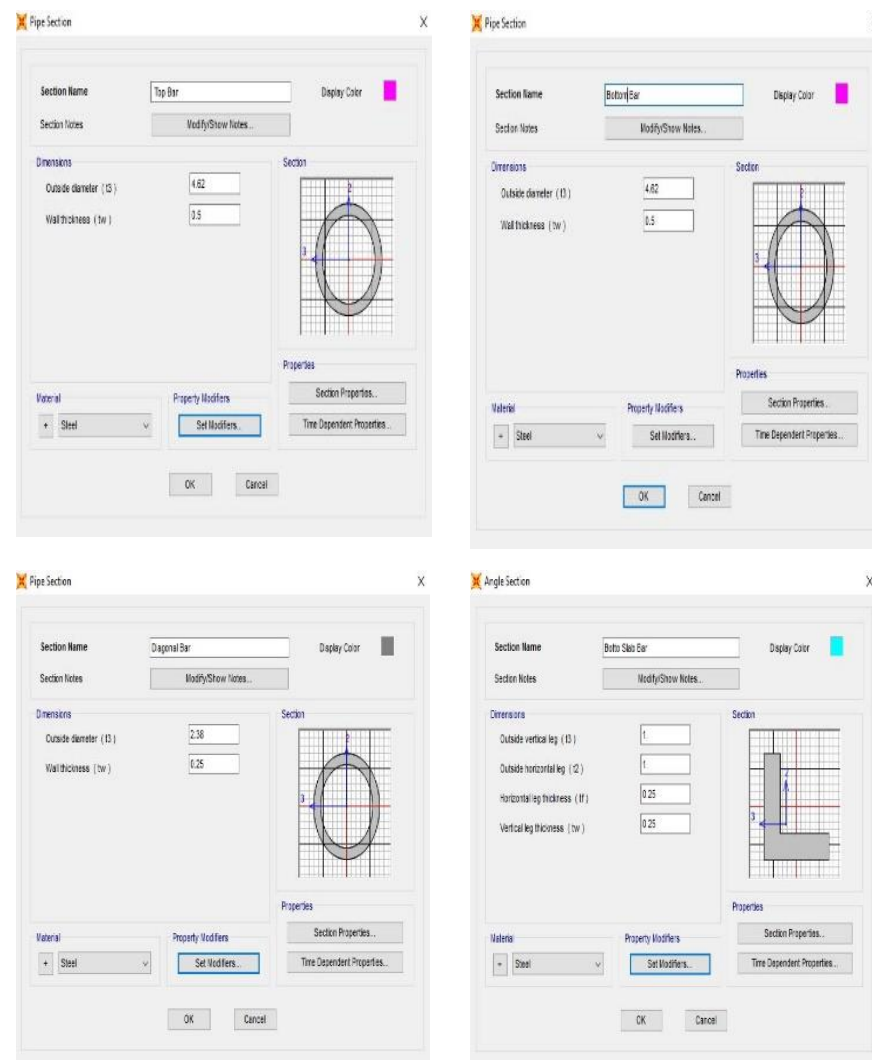

C. Rubber isolator properties

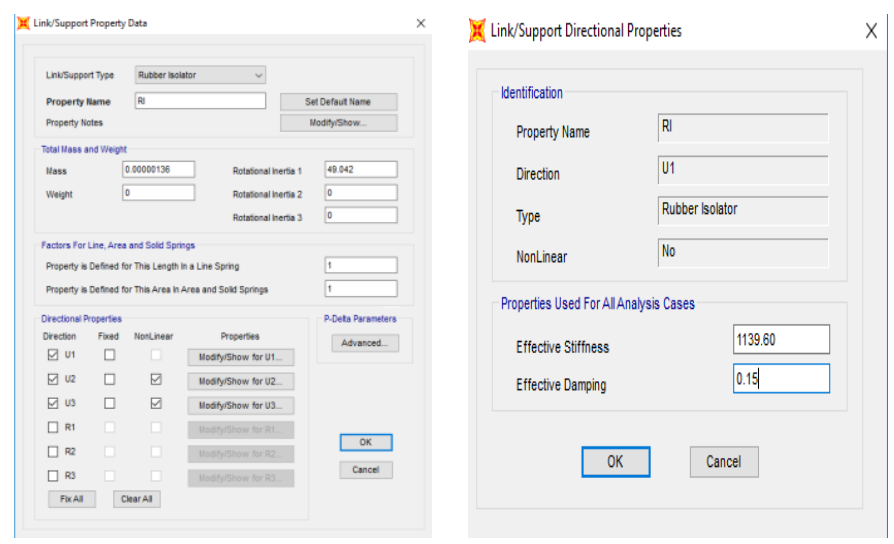



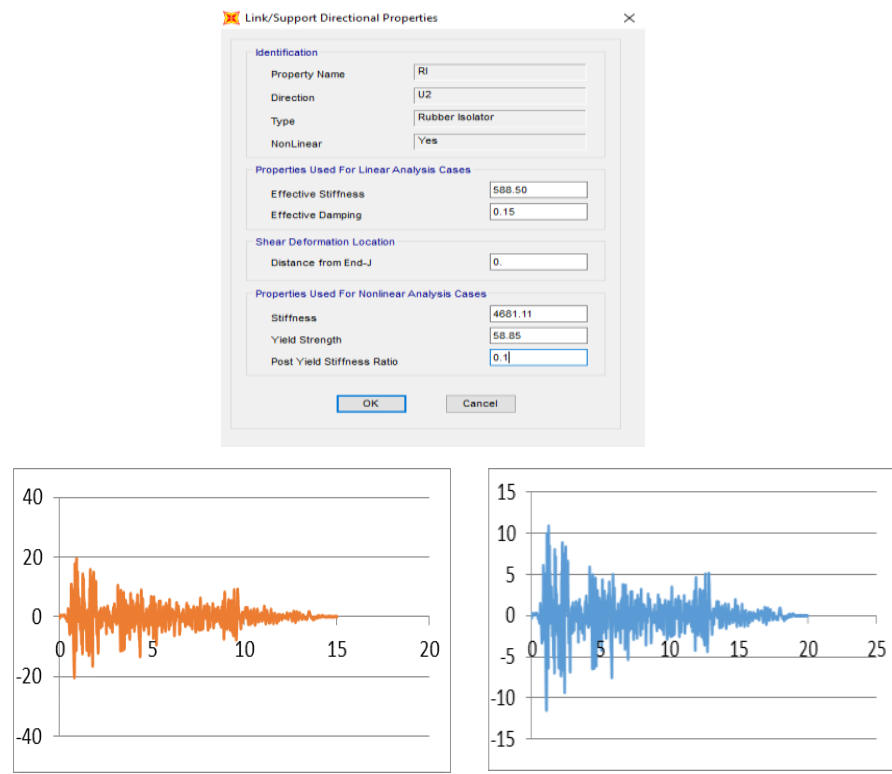

Figure 5. Acceleration vs. Time (Modified El Centro for 15 $\mathrm{sec} ; 20 \mathrm{sec})$

\section{Nonlinear Time History Analysis}

Define $>$ Function $>$ Time history $>$ Input file

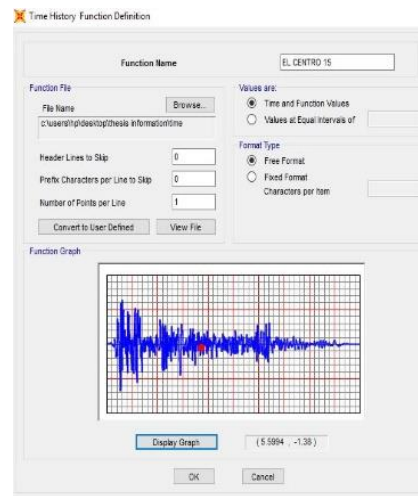

Define > Load case > Add new case $>$ Time history

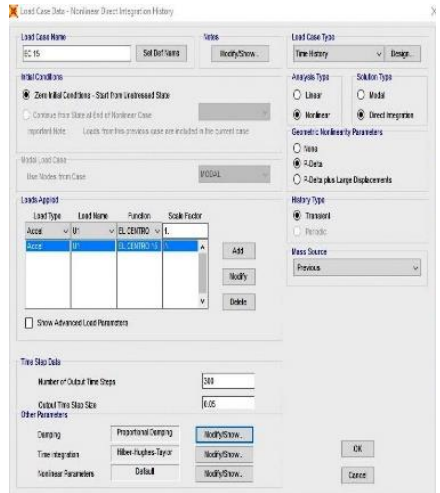

Click the run for analysis. After analysis we get the displacement from.

Display > Plot function > Displacement for time history at maximum time.

\section{DYNAMIC ANALYSIS RESULTS}

\section{A. Displacement vs. Time Curves}

Mid-point displacement vs time curve for $15 \mathrm{sec}, 20 \mathrm{sec}$ with and without isolator in $\mathrm{Y}$ direction.
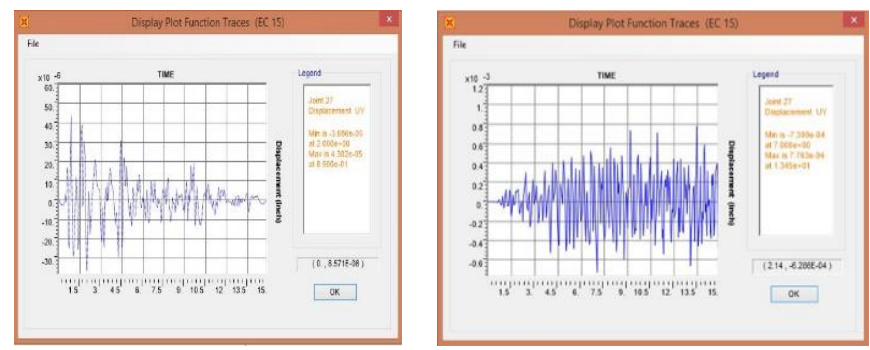

Figure 6. Mid-point displacement vs time curve in $\mathrm{Y}$ axis $(15 \mathrm{sec})$
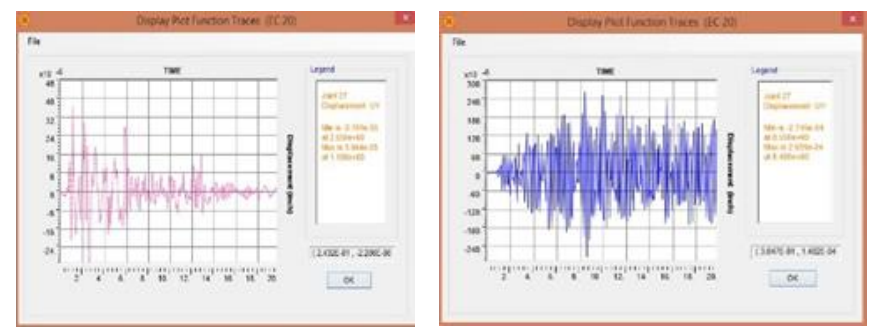

Figure 7. Mid-point displacement vs time curve in $\mathrm{Y}$ axis $(20 \mathrm{sec})$

Table 1. Difference Maximun Displacement between with and without Isolatoin in $\mathrm{Y}$ axis

\begin{tabular}{|c|c|c|c|c|c|c|}
\hline \multirow[t]{2}{*}{$\begin{array}{c}\text { Durat } \\
\text { ion } \\
(\mathrm{sec})\end{array}$} & \multicolumn{2}{|c|}{ 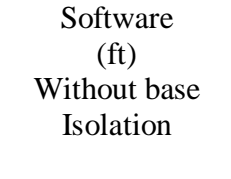 } & \multicolumn{2}{|c|}{$\begin{array}{c}\text { Software } \\
(\mathrm{ft}) \\
\text { With Base } \\
\text { Isolation }\end{array}$} & \multicolumn{2}{|c|}{$\begin{array}{l}\text { Difference of } \\
\text { with and } \\
\text { without } \\
\text { isolation } \\
\text { (ft) }\end{array}$} \\
\hline & $\begin{array}{c}\operatorname{Max}(+ \\
\text { ve) }\end{array}$ & $\begin{array}{c}\text { Max(- } \\
\text { ve) }\end{array}$ & $\begin{array}{l}\operatorname{Max}( \\
+\mathrm{ve})\end{array}$ & $\begin{array}{c}\operatorname{Max}(- \\
\text { ve) }\end{array}$ & $(+\mathrm{ve})$ & $(-\mathrm{ve})$ \\
\hline 15 & $\begin{array}{c}0.0000 \\
44\end{array}$ & $\begin{array}{c}0.0000 \\
37\end{array}$ & $\begin{array}{c}0.000 \\
77\end{array}$ & $\begin{array}{c}0.000 \\
73\end{array}$ & $\begin{array}{c}0.000 \\
73\end{array}$ & $\begin{array}{c}0.000 \\
69\end{array}$ \\
\hline 20 & $\begin{array}{c}0.0000 \\
37\end{array}$ & $\begin{array}{c}0.0000 \\
31\end{array}$ & $\begin{array}{c}0.000 \\
26\end{array}$ & $\begin{array}{c}0.000 \\
28\end{array}$ & $\begin{array}{c}0.000 \\
22\end{array}$ & $\begin{array}{c}0.000 \\
25\end{array}$ \\
\hline
\end{tabular}
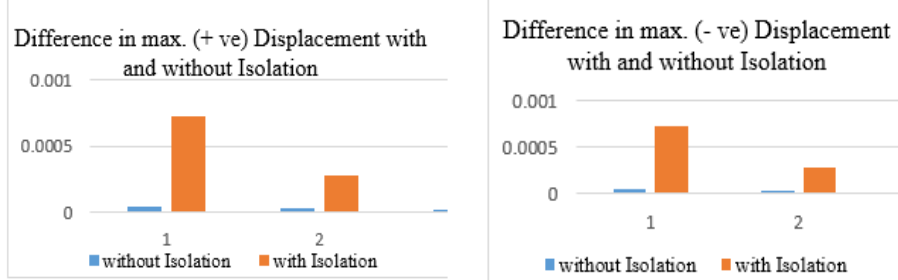

Figure 8. Difference in maximum negative displacement with and without isolation in $\mathrm{Y}$ axis

\section{B. Acceleration vs. Time Curves}

Mid-point acceleration vs time curve for 15, $20 \mathrm{sec}$ with and without isolator in $\mathrm{Y}$ axis 


\section{International Journal of Engineering Applied Sciences and Technology, 2020 \\ Vol. 5, Issue 3, ISSN No. 2455-2143, Pages 101-106 \\ Published Online July 2020 in IJEAST (http://www.ijeast.com)}

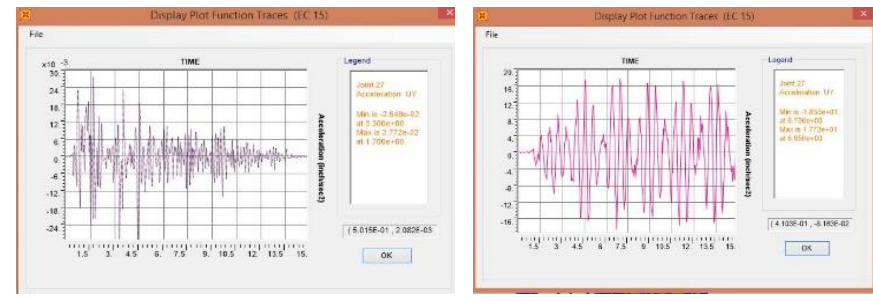

Figure 9. Mid-point acceleration vs time curve in $\mathrm{Y}$ axis

$(15 \mathrm{sec})$
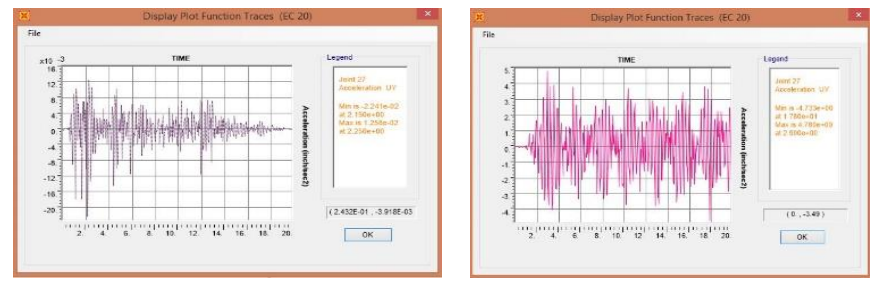

Figure 10. Mid-point acceleration vs time curve in $\mathrm{Y}$ axis $(20 \mathrm{sec})$

\section{CONCLUSIONS}

The work comprises development of working knowledge on SAP 200018 and its application in the dynamic analysis of simply supported bridge. For different El centro $(15,20 \mathrm{sec})$ earthquake data it is found that in every cases displacement is larger when isolator is used. From this results it is found that 15 sec El centro earthquake is more risky for the bridge than $20 \mathrm{sec}$ and using the base isolator at one end of the bridge was not much helpful in earthquake response. The properties of the isolator used in this study was also assumed and it was used at one end of the simply supported bridge.

\section{SUGGESTIONS}

Suggested to the designers to ponder about the participation of structural elements in the seismic isolation global solution, given that characteristics such as lateral restoring capability are an intrinsic part of the entire structural system and not of each component. As an alternative to conventional rubber isolators such as high damping rubber bearing and lead rubber bearing, smart rubber bearing systems with shape memory alloys (SMAs) have been proposed in recent years. As a class of smart materials, shape memory alloys show excellent re- cantering and considerable damping capabilities which can be exploited to obtain an efficient seismic isolation system

\section{ACKNOWLEDGEMENT}

Would like to thank all the faculty members of Civil Engineering Department for their support and guidelines. We are also thankful to the support staff and administrative staff who managed so many issues during the work.

\section{REFERENCES}

1. Guerreiro, L., Ferreira, J. P., Colato, G. P., Castellano, G., \& Baldo, P. (2005, January). Base isolation for seismic protection - the new hospital in Lisbon. In IABSE Symposium Report (Vol. 90, No. 2, pp. 3542). International Association for Bridge and Structural Engineering.

2. Parducci, A., \& Mezzi, M. (1991, November). Seismic isolation of bridges in Italy. In Proceedings of the Pacific Conference on Earthquake engineering, New Zealand (Vol. 20423).

3. Unjoh, S., \& Ohsumi, M. Earthquake Response Characteristics of Super-Multi-Span Continuous Menshin (Seismic Isolation) Bridges and the Seismic Design. ISET Journal of Earthquake Technology, Paper, (377), 95-104.

4. Jangid, R. S. (2004). Seismic response of isolated bridges. Journal of Bridge Engineering, 9(2), 156-166.

5. Pagnini, L. C., Ballio, G., \& Solari, G. (1998). Modelling and nonlinear seismic analysis of bridges with aseismic devices. European Earthquake Engineering, 12, 19-29.

6. Tongaokar, N. P., \& Jangid, R. S. (2000). Earthquake response of seismically isolated bridges. European Earthquake Engineering, 14(1), 48-58.

7. Turkington, D. H., Carr, A. J., Cooke, N., \& Moss, P. J. (1989). Seismic design of bridges on lead-rubber bearings. Journal of Structural Engineering, 115(12), 3000-3016.

8. Turkington, D. H., Carr, A. J., Cooke, N., \& Moss, P. J. (1989). Design method for bridges on lead-rubber bearings. Journal of Structural Engineering, 115(12), 3017-3030.

9. Ebnesajjad, S. (2013). Introduction to fluoropolymers: materials, technology and applications. William Andrew.

10. Haque, M. N., Bhuiyan, A. R., \& Alam, M. J. (2010, August). Seismic response analysis of base isolated highway bridge: Effectiveness of using laminated rubber bearings. In IABSE-JSCE Joint Conference on Advances in Bridge Engineering-II (Vol. 336).

11. Lee, G. C., Kitane, Y., \& Buckle, I. G. (2001). Literature review of the observed performance of seismically isolated bridges. Research progress and accomplishments: multidisciplinary center for earthquake engineering research, 51-62.

12. https://doshinrubber.com/lead-rubber-bearing/ 
13. Jankowski, R., Wilde, K., \& Fujino, Y. (1998). Pounding of superstructure segments in isolated elevated bridge during earthquakes. Earthquake engineering \& structural dynamics, 27(5), 487-502.

14. Kunde, M. C., \& Jangid, R. S. (2003). Seismic behavior of isolated bridges: A-state-of-the-art review. Electronic Journal of Structural Engineering, 3(2), 140-169.
15. Priestley, M. J. N., \& Grant, D. N. (2005). Viscous damping in seismic design and analysis. Journal of earthquake engineering, $9(\operatorname{spec} 02), 229-255$ 